the soldiers. The staff naturally consisted of specialists in every branch of medicine, and I then discovered how advantageous it was to my mental patients to refer them to other members of the medical unit for advice in regard to any physical disabilities from which they suffered. My own knowledge was enriched, and the patient benefited by the consultations. Such a privilege should be made available in every mental hospital, and already is in many of them.

The complete union of psychiatry and general medicine can only be effected when the existing lunacy laws are so amended as to make it possible to treat the psychoses without legal formalities apart from institutions devoted exclusively to these disorders. The exclusion of mental cases from the great teaching hospitals which have special wards for every other type of illness is largely responsible for the divorce between psychiatry and medicine. That it is quite possible to treat many forms of psychosis in a hospital ward was demonstrated in an article in the British MEDICAL Joursal by Dr. Comrie. ${ }^{1}$. Under present conditions of treatment the term "insanity" has come to carry with it the suggestion of chronicity, detention, legal pitfalls, huge institutions filled with incurable patients, degeneracy, and forms of illness for which " nothing can be done." At the outset of a student's career an impression of this kind must ineritably be created in his mind from the fact that he learns nothing of the psychoses, apart from his few visits to the asylum, where the majority of cases produced for demonstration are of the chronic and incurable type; and in his subsequent career, whether as specialist or general practitioner, he takes no part in the treatment of the psychoses which reach any degree of intensity. An entirely fresh point of view would be gained if in his daily work he came into contact with cases of mental disorder. He would learn, above all things, that many morbid mental states are due to the same pathological conditions as are the symptoms of the various svistemic diseases, and amenable to the same methods of treatment. In the out-patient department, moreover, he would see a type of case which he will be called upon to deal with daily in his consulting room, and gain some knowledge of the treatment of the psychoneuroses-conditions which will bulk largely in his practice.

Similarly, in every urban area provision should be made for the treatment of the psychoses in their acute and early stages, and it is much to be hoped that this will be divorced entirely from the Poor Law. There is no possible reason why mental disorder should be tainted with pauperism as it is at present. The municipal health authorities which now deal with fevers and tuberculosis should obriously be entirely responsible for the care of the mentally sick who require in-patient treatment. With a suitable alteration of the law it should be possible also to treat certain certifiable cases by a simple system of notification in nursing homes. These more enlightened methods would naturally fit in with the doctor's experience as a student, and make it much easier to deal with mental cases to the satisfaction of the relatives.

I have aimed to show that if psychiatry is to progress it can no longer remain an isolated specialty; the solution of its problems requires the full co-operation of workers in erery sphere of medicine, and this must naturally include those who are concerned in the prevention rather than the cure of disease. Mental hygiene cannot be dissociated from physical or general hygiene. A French psychiatrist has expressed the view that the causation of mental affections is dominated by three great social scourges: tuberculosis, alcoholism, and syphilis. These, he feels, are the chief infections whose influence is felt in the production of mental disorder, not only in its subjects but in the descendants. Certainly it is to-day firmly established that we profit, both mentally and physically, from the good health of our ancestors, and it is also equally true that we are the rictims of their maladies, and more especially their chronic infections. The endeavours of our medical officers of health to stamp out syphilis would, if successful, considerably diminish the incidence of admissions to our asylums and would probably diminish the occurrence of

2 British Medical Journal, September 27th, 1924, p. 551. mental weakness in the coming generations. Here, also, educationists and religious teachers have a serious responsibility, and there should be no hesitation in teaching young people the elementary facts of sexual hygiene. The subject of prevention is, of course, inexhaustible, and I can do no more than mention the fact that the present and future mental health of the community is closely connected with everything concerning the general standard of physical health and the conditions under which the people live.

It will be a long time before the prejudices which surround the subject of mental disorder are dissipated. We look forward to the time, however, when the public learn to regard this disease as naturally as any other, and when they learn that it is produced by causes similar to those which are responsible for physical maladies. If medical practitioners were consulted by their patients when the first symptoms of mental disorder appeared, I am sure that ordinary physical remedies, rest, and psycho-therapeutic conversations which would enable patients to unburden their minds, would arrest many cases which now drift into serious states before advice is taken. It is much to be hoped, moreover, that when hospital care is considered necessary mental patients will be as willing as the subjects of physical illness to undergo in-patient treatment without apprehension and a sense of social disgrace, whether it be in the wards of a general hospital, special clinics for the treatment of uncertified cases, or separate pavilions connected with urban mental hospitals. The future of the nation is ultimately dependent upon a healthy and vigorous mental reaction on the part of its citizens, and for this reason no effort should be spared to raise the general standard of mental health.

\section{THROMBO-ANGIITIS OBLITERANS.}

$$
\text { BY }
$$

E. D. TELFORD, F.R.C.S.

PROFESSOR OF SYSTEMIATIC SURGERY, UNIVERSITY OF MANCHESTER; AND

JOHN S. B. STOPFORD, M.D., PROFESSOR OF ANATOMY, UNIVERSITY OF MANCHESTER. (With Special Plate.)

First recognized in 1879 by v. Winiwarter and described by him as endarteritis obliterans, this disease has, during recent years, been more fully described by Buerger ${ }^{1}$ of New York, who has given it the name of thrombo-angiitis obliterans. This name is the more accurate, because the disease is prone to involve veins as well as arteries.

The condition appears to have received little attention in this country. It can, however, hardly be rare, since no fewer than four cases have occurred in the practice of one of us within the last twelve months. It is with the object of drawing more widespread attention to this very grave disease that the following four cases are reported in considerable detail, together with the histological findings in the three cases which came to amputation on account of gangrene.

A study of Buerger's cases shows that the broad clinical features of the discase are as follows: It is a disease of the larger blood vessels which, although of unknown origin, shows the histological features of an inflammatory lesion. The vessels mainly affected are the larger arteries of the limbs, but the disease is seen also to some extent in the veins. Thrombosis occurs and is followed by organization of the clot. This produces grave embarrassment of the circulation, alleviated to a variable extent by the usual canalization of the fibrous tissue.

The disease occurs almost exclusively in males (99 per cent. in Buerger's cases), and the onset is commonly in the third decade. The lower limbs are affected much more commonly than the upper: it is the rule for the discase to begin in one lower extremity and to appear in the opposite limb at a date which may be from one to four years later than the first onset.

The disease produces symptoms such as would be cxpectid in a limb in which the arterial circulation is being carried on only with the utmost difficulty. The first symptom to attract attention is pain, produced and increased by 
exertion, and situated usually in the foot or calf. At this stage the absence of pulse in the dorsalis pedis, posterior tibial, popliteal, or even femoral artery will be noted. Later in the case a peculiar rubor, oedema, and trophic lesions are likely to develop, and in the more severe forms gross gangrene calling for amputation.

The duration of the disease is very variable-gangrene may occur early or may be warded off for as long as twelve years. No less than 52 per cent. of Buerger's cases came to amputation on account of gangrene.

The cause of the disease is unknown; there is no evidence that syphilis has anything to do with it. Buerger's patients were almost without exception Jews, and the disease has in fact been called "Die Hebraische Krankheit." This, however, can be no more than a topographical accident; each of our four cases was British born.

\section{Symptoms and Histological Appearances.}

Our first case was B., a male aged 40 years, clerk, British, seen December 17th, 1923; he gave the following history. When 30 years of age he noticed pain in the right calf; this pain came on after walking a short distance and passed off quickly with rest. Within four months he noticed similar pain in the left calf, and in a further six months the pain in both legs was severe and crippling. In this state he continued, with but slight aggravation, for a further two years. At the end of this time he could walk only short distances with the help of crutches. He next found that the right leg was slightly swollen and there was "purple discoloration of the toes." $\mathrm{He}$ began with massage and carried it on for five years; during this time he had a trophic sore on the front of the ankle, which took eighteen months to heal. The left leg continued to give pain, but got no worse. Two years ago, however, the left leg began rapidly to get worse and the pain was continuous in the calf, foot, and ankle. The foot was "always stone cold," and a small septic focus appeared on the inner side of the great toe.

Except for digestive trouble suggestive of duodenal ulcer, his previous medical history was good and the Wassermann reaction was negative. He had in his earlier days been a most enthusiastic fisherman, and had spent much time in wading, a habit to which he firmly attributes his present troubles.

Prcscnt Condition.-Right lower extremity: The whole limb is much wasted from disuse, its muscular power is good and sensation everywhere normal. The femoral pulse is normal, but the popliteal is barely to be felt, and there is no pulse below this level. Left lower extremity: Slightly wasted, but muscular power lovel. and sensation normal. The whole foot is dull red in colour; there is solid oedema about the dorsum of the foot and a small ; there is solid oedema about the dorsum of the foot and a small onychia
of the great toe. There is no pulsation in the common femoral artery or at any point below this. He insists that it is most comfortable when cool and dependent, and says that he gets a little sleep by hanging this leg naked over the side of the bed.

In January, 1924, this patient was seen during the night with severe abdominal pain, and was found to be suffering from a perforative lesion, presumably of the duodenum, as he had for some time past shown symptoms suggestive of duodenal ulcer. Laparotomy was done and a large perforation of the anterior wall of the first stage of the duodenum was sutured; the operation was completed by posterior gastro-enterostomy. As far as his condition allowed, an exploration was made to ascertain the condition of the intra-abdominal vessels. It was then evident that no pulsation could be felt in the common, internal, or external iliac arteries of the left side; these vessels were plainly to be felt as immobile cords.

He made an excellent recovery from the operation, but in April, 1924, ten and a half years from the onset of the disease, the whole of the left foot became rapidly gangrenous, the condition having spread from the old onychia of the great toe. A supracondylar amputation was done through the left thigh on the following day; the femoral artery at the level of the section was open and normal. The wound healed without incident.

\section{Histological Examination.}

On dissecting the amputated limb, isolation of the large blood vessels was found to be difficult on account of dense perivascular adhesions, which were particularly strong in the popliteal space. Although the femoral artery was patent, almost the whole length of the popliteal artery was occluded. Sections of this vessel showed the lumen to be filled with loosely arranged fibrous tissue (Fig. 1) containing a number of minute channels, all of which possessed an endothelial lining and some a thin muscular tunic (Fig. 2). The intima was a little thickened and slight fragmentation and fibrillation of the internal elastic lamina was reen. The amount of muscular tissue in the media was much reduced and the fibres separated by fibrous tissue (Fig. 3). The adventitia was markedly increased in thickness, and contraction of this had caused considerable reduction in the diameter of the vessel. The popliteal vein exhibited some irregular thickening of the intima (Fig. 5) and part of the lumen was occupied by a recent thrombus. Fibrous tissue was present in considerable amount between the muscle fibres of the media and the outer coat was greatly thickened. The changes found in the posterior tibial artery were almost identical with those described in the case of the popliteal, but less thickening of the intima was discovered in the anterior tibial vessels and the dorsalis pedis artery was normal. A section of the lower part of the internal saphenous vein manifested changes similar to those found in the popliteal artery.

This case is very typical, running a course of eleven years so far with very slowly progressive deterioration. It is noteworthy that it was possible during life to verify the total thrombosis of the common, internal, and external iliac arteries, and the history illustrates a point which has been evident in other recorded cases-that is, the limb which is to be affected later tends ultimately to become the worse.

Case ir.

S., male, aged 52 years, electrician, British, seen February 17th, 1924. This man had never had a day's illness in his life until the beginning of the present trouble. He had latterly complained for one year of pain in the right calf. This pain came on after the slightest exertion and was immediately cured by rest. The patient had thought it to be rheumatism and had not sought any advice. had thought it to be rheumatism and had not sought an ad ice.
One week before he was seen by us a small black patch had
appeared on the inner side of the great toe and a second similar appeared on the inner side of the great toe and a second similar
patch developed over the heel. Within a few days the whole foot and ankle were in a state of gangrene.

His general condition was very grave owing to toxaemia and exhaustion from pain, but examination disclosed no evidence of the more usual causes of gangrene. His heart, though rapid, was more usual causes of gangren sign of arterial scierosis and his otherwise normal; he showed no sign of sugar. The Wassermann urine contained neither.

A supracondylar amputation of the right thigh was done at once, and he made an excellent recovery.

In this case complete occlusion of the lower part of the popliteal artery for a distance of about three-quarters of an inch was found, and sections at this level revealed changes similar to those recorded in the first case, except for the greater density of the tissue occupying the lumen. Strong adhesions fixed the popliteal vessels, which were excised with difficulty, to the surrounding tissues. Only early manifestations of the disease were found in the anterior and posterior tibial arteries, there being a cellular infiltration of the walls and a little fibrosis without any thrombosis. The internal saphenous vein showed advanced fibrosis of the media and adventitia, but only early evidence of organization of the thrombus in the lumen.

This case, although occurring in an older man, appears also to be an example of thrombo-angiitis obliterans. On the results of the clinical examination of the patient and on the histology of the vessels, no other cause appears at all possible.

Case IIr.

V. S., male, aged 37 years, clerk, British, seen September, 1924, gave the following history : He had always been a very vigorou and robust man until three years ago, when he noticed a sudden pain in the left calf on walking. He was able to walk about two pundred jards and was then obliged to rest. This condition was the only feature during one year; at the end of that time an the only feature during one year; at the end This pain, which exactly similar pain came in the right calf. This pain, which
spread to the foot and produced " burning of the toes," gradually became very severe. It came also when he was at rest and began to destroy his sleep. It has continued to be present in a wellnigh intolerable severity, and its progress has been in no way altered by the most varied and extraordinary treatments before we saw him.

Examination of the left lower extremity shows that there is no

pulse in the common femoral artery and no pulse at any point below this. The superficial femoral artery is felt in the lower angle 


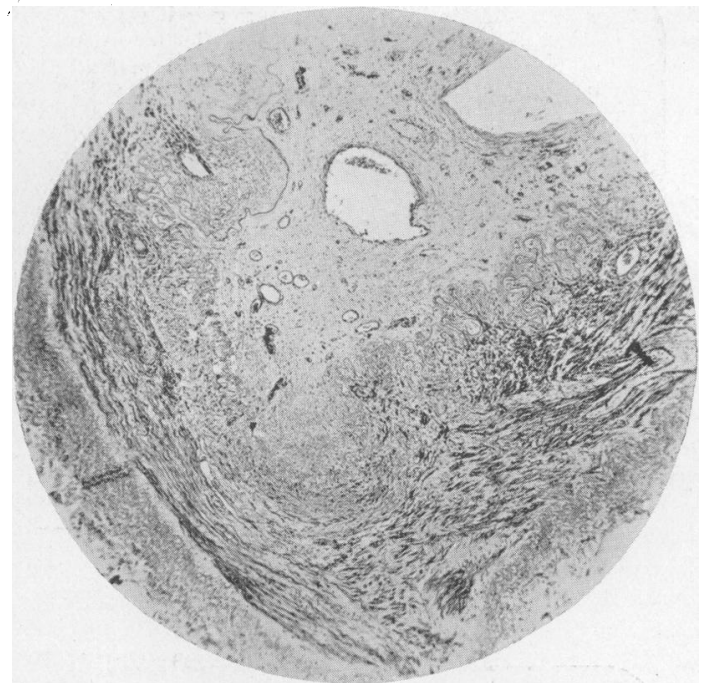

FIG. 1.-Section of popliteal artery in Case I. The character of the occluding tissue, the thickening of intima, and the fibrosis of the media are well seen.

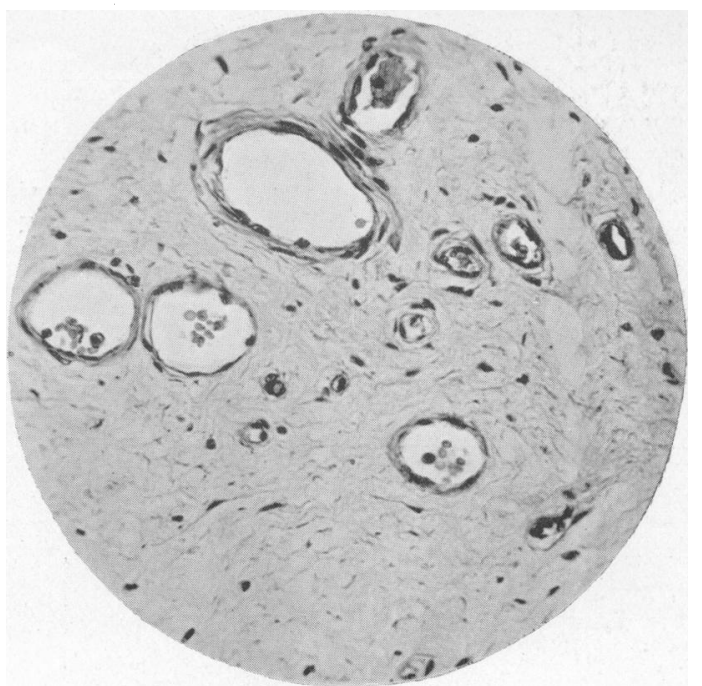

Fig. 2.-High power view of the occluding tissue in popliteal artery in Case I. A number of channels lined by endothelium, and a few
possessing a scanty muscular tunic, are seen.

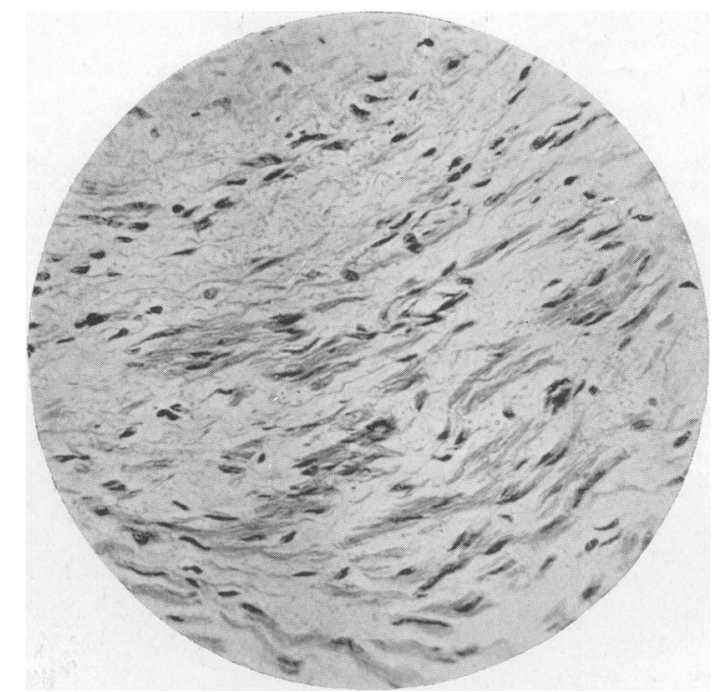
FIg. 3.- Section of tunica media of popliteal artery in Case I. The

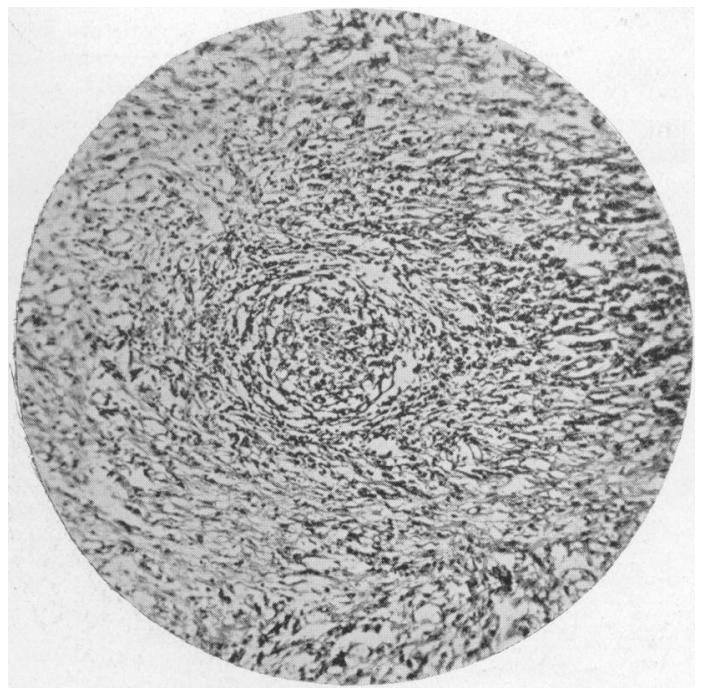

FIG. 4.-Section of tissue occluding lumen of the popliteal artery in Case Iv. A collection of lymphocytes occupies the centre of the field.

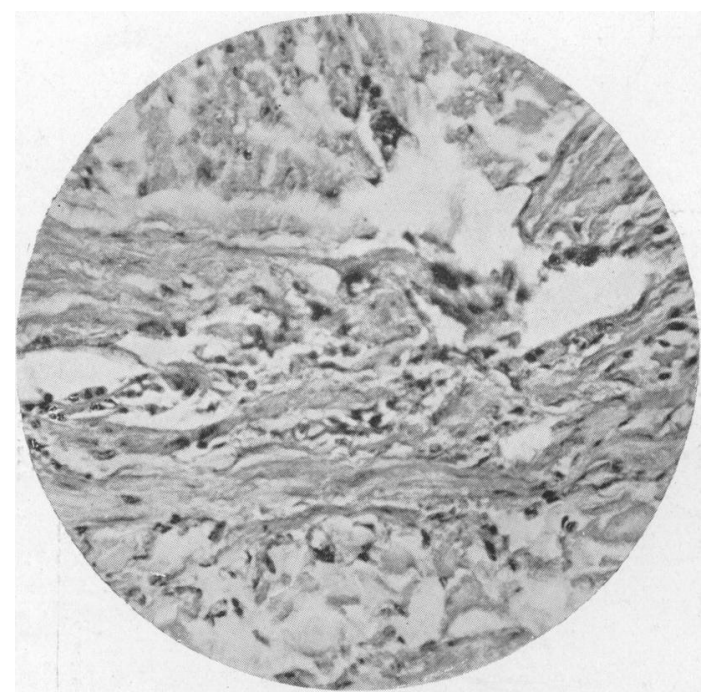

FIG. 5.-Section of the wall of the internal saphenous vein in Case I, showing cellular infiltration of the tunica media. 
of Scarpa's triangle as a stiff cord. The whole circulation of this limb is blanches much on elevation. There are no trophic changes, muscular power and sensation are normal, but it is noted that the deep reflexes are somewhat increased.

The right lower extremity, which is the chief site of pain, shows a pulse in the common and superficial arteries, but no popliteal pulse is to be felt, neither is there any pulsation in the leg or foot. The condition is in other respects exactly as on the left side. It is again interesting to note that the left leg, in which the dis is ain in the disease first began, is at present much the better from the patient's point of view, although the loss of the puls
extensive. The Wassermann reaction was negative.

This case is a very typical example of thrombo-angiitis obliterans. It has shown during three years a slow and steady aggravation. There are at present only pain and loss of pulse, but it is greatly to be feared that it may run a course to final gangrene.

\section{Case IV.}

H., male, aged 45, clerk, British, seen September 28th, 1924. The disease began twelve months ago with pain in the great too of the left foot, followed very shortly by sudden acute pains in the shin and knee-joint. After walking a short distance there was cramp in the left calf, together with a feeling " as if there was a tight band round the leg below the knee." These symptoms always passed off after a few moments' rest. He noted next that his foot was "stone cold" and could never be revived by any of the measures which he took to keep it warm.

Three months before he was seen a small "blood blister" Three months before he was seen a small "blood blister"
appeared on the third toe by the side of the nail, and from this appeared on the third toe by the side of the nail, and from this
point there progressed an ever-increasing dry gangrene. The whole point there progressed an ever-increasing dry gangrene. The whole the attempted line of demarcation a feeble inflammatory reaction with a little very foul discharge.

Examination of the leg showed that the femoral pulse was present and that a slight pulse could be felt at the apex of Scarpa's triangle. No pulse could be felt at any point in the leg below this Sensation throughout the limb was normal but muscular power was poor from disuse and there was flexion-contracture of power was poor from disuse and there was flex

The patient's general condition was poor owing to pain and toxaemia, but beyond very foul teeth he showed no other sign of disease. The urine was normal; his heart showed no lesion, and he had a blood pressure of 120 systolic and 80 diastolic. His previous medical history was excellent and the Wassermann reaction was negative.

A supracondylar amputation was performed, and it was noted that the main artery on the face of the stump was blocked by a brown, partially organized clot. There was an entire absence of haemorrhage and no ligature was employed. The stump healed haemorrhage and

In this case there was complete occlusion of the whole popliteal artery, and microscopic sections revealed a similar picture to that seen in the first case, but in addition to the other features a group of lymphocytes was found in the tissue occupying the lumen (Fig. 4). This collection of lymphocytes had an appearance not unlike a tubercle, and such structures have been observed by Buerger, but he describes the cells as polynuclear leucocytes. Fibrous tissue had replaced much of the muscular tunic of the popliteal vein, but only a small thrombus, which was becoming organized, was found in the lumen. The posterior tibial artery and vein were also completely occluded except for the usual small channels in the organized thrombus. There was considerable fibrosis of the media and adventitia; this was found also in the anterior tibial artery, but the latter vessel was still patent. The changes seen in the anterior tibial vein consisted of cellular invasion of the media and adventitia only. The muscular tissue of the wall of the internal saphenous rein was largely replaced by fibrous tissue and a recent clot was to be seen in the lumen.

There can be little doubt that this case is an example of thrombo-angiitis obliterans. The disease began in a man 44 years of age, of good physique and with an excellent medical history. It ran a typical but somewhat rapid and disastrous course. It will be a matter of great interest to observe whether any similar changes occur in the right lower extremity, which is fortunately so far unaffected.

\section{Summary of Pathologrcal Observations.}

The changes found in the three limbs examined after amputation correspond clesely to those described by Buerger, and manifest the various stages of the disease. At the outset there appears to be a lymphocytic, not a polynuclear leucocytic, invasion of the coats of the arteries and veins. The cells are replaced by fibrous tissue and new ressels may be seen extending through the adventitia to the media. Whilst these changes are proceeding parts of the lumen become occupied by a clot, which is gradually organized. In the obliterating connective tissue a number of small channels are to be found which have a lining of endothelium, and, surrounding this, some possess a thin coat of smooth muscle. After the thrombosis has occurred and whilst organization is proceeding, collections of lymphocytes not unlike tubercles often make their appearance and persist until they are replaced by fibrous tissue. There is commonly some irregular thickening of the intima, but as a rule only very slight proliferation or fibrillation of the internal elastic lamina. At a later stage the fibrous tissue in the lumen has a denser appearance, but this may be due, at any rate partly, to the contraction of the newformed fibrous tissue in the media and adventitia, which not infrequently shows hyaline or other degenerative changes. This contraction may be an important factor in the production of gangrene, since it leads to compression and occlusion of many of the newly formed smaller channels in the connective tissue in the lumen.

The histological examination indicates that the disease is much more widespread than the clinical picture would suggest, both superficial and deep veins and arteries being involved, but all the vessels in one region are not equally affected. Case II illustrates this best, since late stages of the disease were seen in the popliteal artery and only early manifestations in the anterior and posterior tibial vessels. The constancy of advanced changes in the popliteal artery is significant, and may be due to the strain to which it is constantly subjected by movements of the knee-joint. On the other hand, the constancy of changes in the popliteal artery in amputated limbs may be misleading, since obstruction of this artery is most likely to result in gangrene. There is no evidence to suggest that the disease is secondary to any affection of peripheral nerves. The microscopic findings are those of $\mathbf{a}$ chronic inflammatory lesion, and suggest a microbic origin of the disease. Rabinowitz ${ }^{2}$ claims to have isolated a Gram-negative, rodshaped and beaded organism, and to have produced by the bacillus the same lesion in the ears and feet of rabbits as that which was present in the leg of a human being. These experiments require repetition, and further investigation is urgently required before the origin of the disease can be decided.

It is impossible to resist the conclusion that in this rare and very grave disease we have a definite clinical entity. Of its cause we know nothing. Cold, malnutrition, racial peculiarity, and even cigarette smoking, have been indicted, and there is the inevitable "toxic" theory. It is much to be regretted that no abortive or curative treatment is as yet available, and it is hardly to be expected where structures such as main arteries are already plugged and destroyed by scar tissue.

\section{TreatMent.}

Treatment can at present be only such as is dictated by the perilous vitality of the limb-rest, massage, and, above all, protection from any form of injury. It is for this reason very essential that a correct diagnosis be made early in the history of these cases. Otherwise it is possible that harmful and even disastrous treatment may be applied. One of our cases sustained a trivial electrical burn which took no less than eighteen months to heal, and a second case was in danger of losing his limb in consequence of the advice given by his medical man to apply hot turpentine stupes.

Where gangrene eventually ensues we think it important that nothing less than a supracondylar amputation of the thigh be done. The popliteal bifurcation is wellnigh certain to be blocked, and to amputate at a lower level is to court disaster.

\section{REFERENCES.}

1 Buerger, L.: The Circulatory Disturbances of the Extremities, Including Gangrene, Fasomotor, and Trophic Disorders. W. B. Saunders Company, Philadelphia and London, 1924

Rabinowitz, H. M. : Experiments on the Infectious Origin of Thrombo anglitis Obliterans and the Isolation of a Specific Organism from the Blood Stream. Surgery, Gynecology and Obstetrics, September, 1923, pp. $353-360$. 